\title{
MODELOS ESTEREOQUÍMICOS DE ADIÇÃO À CARBONILA
}

\author{
Bruna S. Martins, Diogo S. Lüdtke* e Angélica Venturini Moro* \\ Instituto de Química, Universidade Federal do Rio Grande do Sul, UFRGS, Av. Bento Gonçalves 9500, 91501-970, Porto Alegre, \\ RS, Brasil
}

Recebido em 13/07/2016; aceito em 30/09/2016; publicado na web em 02/11/2016

\begin{abstract}
STEREOCHEMICAL MODELS FOR CARBONYL ADDITION. The stereochemical control in the generation of new stereogenic centers is of paramount importance in organic chemistry. In this context, diastereoselective additions to carbonyl compounds bearing a stereogenic center at the $\alpha$-position are of particular importance, since an increase in molecular complexity can be achieved by constructing a new bond, together with the introduction of a new stereocenter. Despite the relevance of the topic, it is discussed only briefly in several of the most popular organic chemistry textbooks, or not discussed at all. The present article intends to discuss the evolution of stereochemical models for 1,2-induction and present to students a tool to understand and predict the stereochemical outcome of addition of nucleophiles to aldehydes and ketones bearing a stereogenic center at the $\alpha$-position.
\end{abstract}

Keywords: stereochemistry; diastereoselectivity; carbonyl compounds; Felkin-Anh; Cram-chelate.

\section{INTRODUÇÃO}

Uma das principais ferramentas para a síntese de moléculas complexas é a utilização de elementos estereoquímicos pré-existentes no substrato para controlar a criação de novos centros estereogênicos, mediante reações diastereosseletivas. ${ }^{1}$ Essa abordagem é particularmente útil em reações de adição de nucleófilos a aldeídos e cetonas, contendo um centro estereogênico adjacente à carbonila. Nesses casos, as duas faces da carbonila são diastereotópicas e a adição de nucleófilos pode levar a formação de dois diastereoisômeros, com formação preferencial de um deles pela influência do centro pré-existente. ${ }^{2}$ A nomenclatura para faces pró-quirais segue as regras CIP (Cahn-Ingold-Prelog), da mesma forma que a nomenclatura de centros estereogênicos. A única diferença é que ao invés da nomenclatura $R$ e $S$, utilizada para designar a configuração dos centros estereogênicos, a nomenclatura $R e$ e $S i$ é utilizada para a atribuição das diferentes faces enantio- ou diastereotópicas de um carbono trigonal. Cada uma das faces é visualizada e uma ordem numérica de prioridade 1-3 é estabelecida, de acordo com as regras CIP. Quando a contagem ocorre em sentido horário, a face é denominada $R e$, enquanto que quando a contagem ocorre em sentido anti-horário, a face é denominada de $\mathrm{Si}$. Os substituintes adjacentes à carbonila serão classificados conforme seu volume e a nomenclatura $\mathrm{R}_{\mathrm{P}}, \mathrm{R}_{\mathrm{M}}$ e $\mathrm{R}_{\mathrm{G}}$ será utilizada nos modelos estereoquímicos apresentados nessa revisão (Esquema 1).

O controle estereoquímico em reações de adição à carbonila é um tópico extremamente relevante, no entanto, não é abordado na maioria dos livros-texto de Química Orgânica, ${ }^{3}$ salvo algumas exceções. ${ }^{4} \mathrm{O}$ intuito do presente trabalho é apresentar de forma didática a evolução dos modelos estereoquímicos de indução 1,2 em reações de adição aos compostos carbonílicos, fornecendo ao estudante um material para complementar seu aprendizado em Química Orgânica.

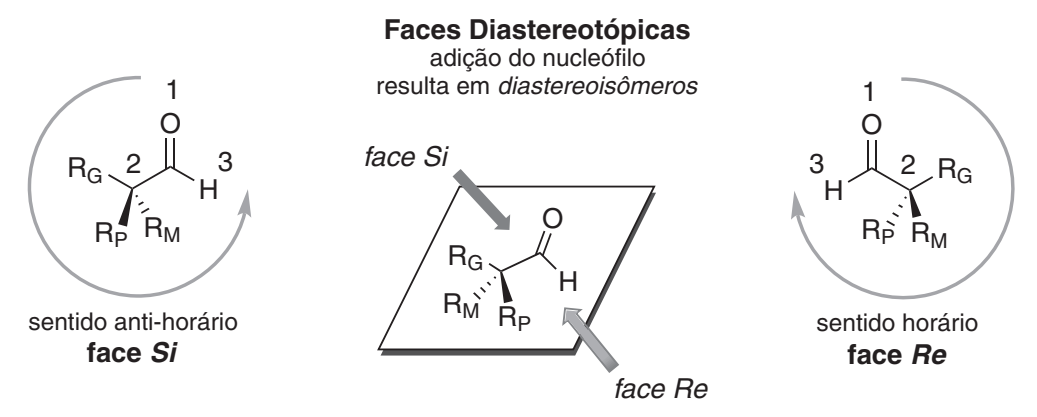<smiles>[R]C(=O)C([R9])[R6]</smiles>

$R_{P}=$ substituinte menos volumoso $R_{M}=$ substituinte de volume médio $R_{G}=$ substituinte mais volumoso<smiles>[R6]C([R8])C([R])(O)[18OH]</smiles><smiles>[R6]C([R6])C([R6])([2H])O</smiles>

diastereoisômeros

Esquema 1 - Faces diastereotópicas e adição de reagentes organometálicos a compostos carbonílicos 
A primeira observação de que reações em substratos possuindo elementos de quiralidade poderiam ocorrer sob influência destes foi descrita por Emil Fischer em 1889, em uma reação de adição de $\mathrm{HCN}$ ao carboidrato L-manose $\mathbf{1}$ (Esquema 2). ${ }^{5}$ Após a hidrólise da cianoidrina, o ácido heptônico correspondente $\mathbf{2}$ foi obtido como único diastereoisômero. Frente a esses resultados, Fischer afirmou: "Segundo meu conhecimento, essas observações fornecem a primeira evidência definitiva de que síntese com sistemas assimétricos ocorrem de maneira assimétrica".

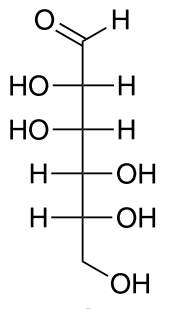

1

L-manose

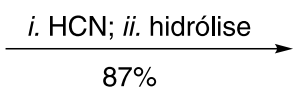

$87 \%$

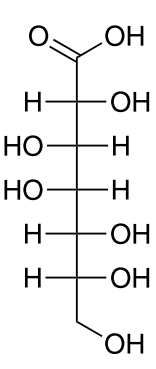

2
Esquema 2 - Primeira evidência de uma reação diastereosseletiva

Após as descobertas pioneiras de Fischer, que foram brilhantemente aplicadas no seu clássico trabalho de elucidação da estrutura das hexoses através das suas sínteses, ${ }^{7,8}$ uma nova visão sobre a importância da estereoquímica e reações envolvendo moléculas quirais se tornou necessária. No entanto, somente na metade do século XX surgiram estudos detalhados e sistemáticos visando explicar o curso estereoquímico de reações de adição a compostos carbonílicos possuindo centros estereogênicos adjacentes. O resultado desses estudos levou à elaboração de modelos estereoquímicos para explicar os resultados experimentais e, principalmente, para prever comportamentos de sistemas ainda não estudados, permitindo dessa forma um maior controle sobre o planejamento sintético.

\section{DISCUSSÃO}

\section{Modelo de Cram (1952)}

No início dos anos 1950, Cram e Elhafez observaram que a adição do reagente de Grignard, iodeto de metilmagnésio, ao aldeído 3, contendo um centro estereogênico adjacente à carbonila, ocorria com formação preferencial de um dos diastereoisômeros (Esquema 3). ${ }^{9,10,11}$

Para explicar esse e outros resultados observados experimentalmente, Cram propôs o primeiro modelo estereoquímico em 1952.

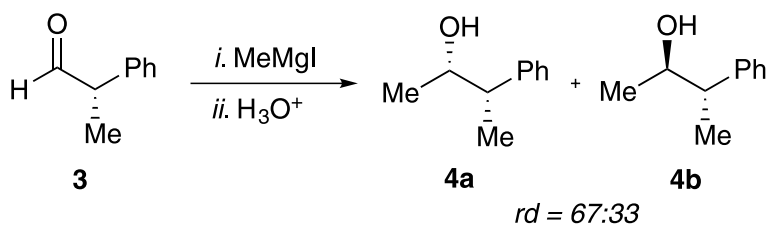

Esquema 3 - Estudos iniciais de Cram

Segundo o modelo de Cram, o resultado estereoquímico poderia ser entendido através do ataque do nucleófilo à conformação em que o grupo mais volumoso encontra-se eclipsado com o substituinte ligado à carbonila, enquanto que o oxigênio carbonílico estaria posicionado entre os grupos pequeno e médio. $\mathrm{O}$ ataque nucleofílico ocorreria perpendicularmente em relação ao plano da carbonila, em sua face menos impedida, ou seja, mais próxima ao grupo $R_{\mathrm{P}}$ (Figura 1$) .{ }^{12}$

\section{Modelo de Cram (1952)}

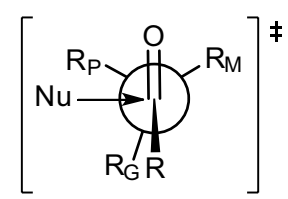

grupo mais volumoso eclipsado com o substituinte $R$

Figura 1 - Modelo de Cram

No caso mostrado no Esquema 1, o grupo fenila $\left(\mathrm{R}_{\mathrm{G}}\right)$ ficaria eclipsado com o hidrogênio do aldeído $(\mathrm{R})$ e a carbonila ficaria alternada entre os substituintes de menor $\left(R_{P}=H\right)$ e médio $\left(R_{M}=M e\right)$ volume (Esquema 4). Dessa forma, o ataque do nucleófilo (MeMgI) ocorreria preferencialmente pela face menos impedida da carbonila, que seria aquela pelo lado do substituinte menos volumoso $\left(R_{P}=H\right)$.

Embora o modelo de Cram tenha sido utilizado com sucesso para explicar um conjunto significativo de resultados, algumas falhas foram observadas, dentre as quais se destacam: (1) os grupos $R_{G} e$ $\mathrm{R}$ encontram-se eclipsados e a significativa repulsão estérica entre eles não é levada em consideração, o que é particularmente válido para o caso de cetonas com centro estereogênico $\alpha$-carbonílico; (2) em vários casos, a escolha de grupos de tamanho similar é um tanto quanto arbitrária, por exemplo, o grupo $\mathrm{CH}_{3}$ é considerado mais volumoso do que um grupo $\mathrm{NH}_{2}$, sem que haja uma clara justificativa.

Em estudos posteriores, Cram propôs a utilização de valores-A, ${ }^{13}$ que estimam o volume estérico de um dado substituinte, para a

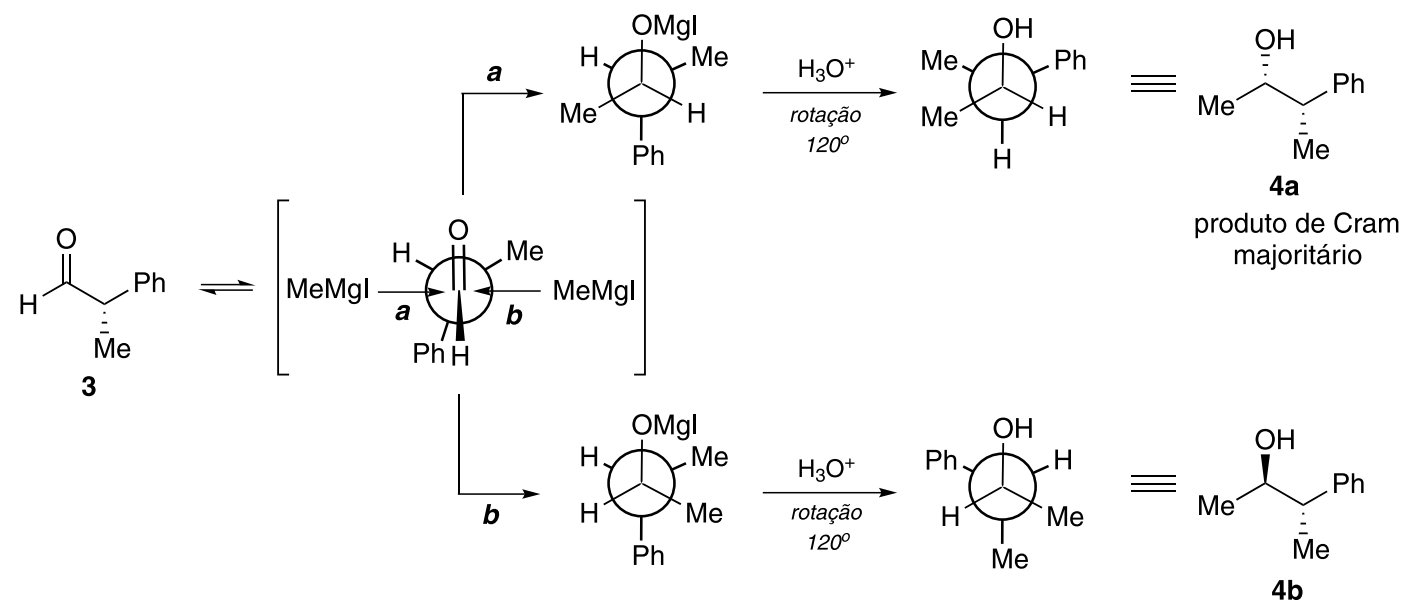


classificação dos grupos presentes no centro estereogênico. Quando cetonas contendo grupos funcionais polares $(\mathrm{OH}, \mathrm{OMe})$ na posição vizinha à carbonila foram estudadas, os grupos seriam classificados de acordo com seus valores- $A$, sendo $R_{P}=O H$ ou $O M e, R_{M}=M e ~ e$ $\mathrm{R}_{\mathrm{G}}=\mathrm{Ph}$. No entanto, o produto majoritário observado nas reações é 6a, enquanto que o modelo de Cram prevê a formação majoritária do produto $\mathbf{6 b}$ (Esquema 5).<smiles>CC(C)(C)[C@](C)(C(=O)[O-])c1ccccc1</smiles>

5<smiles>CC(O)(c1ccccc1)C(C)([18OH])c1ccccc1</smiles>

$6 a$

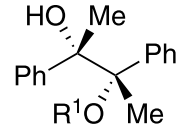

$6 b$

\begin{tabular}{cccc|}
\hline Me-M & $\mathbf{R}^{\mathbf{1}}$ & $\mathbf{6 a}: \mathbf{6 b}$ & rend. 6a (\%) \\
\hline MeMgl & $\mathrm{H}$ & $92: 08$ & 20 \\
MeLi & $\mathrm{Me}$ & $90: 10$ & 50 \\
\hline
\end{tabular}

Esquema 5 - Seletividade na adição de Me-M a cetonas

Frente a esses resultados, surgiu um novo modelo que leva em consideração a complexação do átomo de oxigênio com o reagente organometálico restringindo a conformação durante o ataque do nucleófilo.

\section{Modelo quelado de Cram (1959)}

No modelo quelado de Cram (Figura 2), há a formação de uma estrutura cíclica, com a carbonila e o grupo OR eclipsados, devido à quelação com o metal. ${ }^{14}$ Dessa forma, o ataque do nucleófilo ocorreria pela face menos impedida da carbonila, ou seja, pelo lado do substituinte $\mathrm{R}_{\mathrm{P}}$.

Modelo Quelado de Cram (1959)

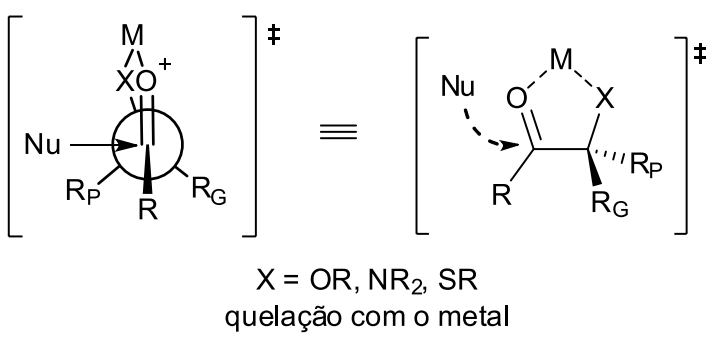

Figura 2 - Modelo Quelado de Cram. Projeção de Newman e vista lateral

Aplicando-se os dois modelos para as reações da cetona $\mathbf{5}$ com nucleófilos organometálicos, observa-se que cada um deles prevê o ataque do nucleófilo em faces opostas da carbonila, e, consequentemente, à formação de diferentes produtos (Esquema 6). O produto observado experimentalmente é 6a, previsto pelo modelo quelado de Cram

\section{Modelo de Cornforth (1959)}

No mesmo ano, o modelo sugerido por Cornforth propõe que compostos carbonílicos que possuem grupo eletronegativo não-quelante no carbono $\alpha$ adotem uma conformação que minimize os dipolos durante o ataque do nucleófilo. ${ }^{15}$ Os autores afirmam que, apesar dessa conformação apresentar grupos eclipsados e estar em baixa concentração no equilíbrio conformacional, a minimização dos dipolos seria o fator principal para a adoção dessa conformação no estado de transição. Dessa forma, no modelo proposto por Cornforth, a adição de um nucleófilo a um composto carbonílico ocorre pela face menos impedida da carbonila, quando a molécula adota uma conformação onde o grupo polar e não-quelante $(X)$ ocupa uma posição antiparalela ao grupo carbonila e eclipsada com o substituinte R (Figura 3).

\section{Modelo de Cornforth (1959)}

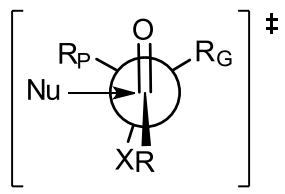

Figura 3 - Modelo de Cornforth

A adição de diferentes reagentes organolítio e organomagnésio a uma série de $\alpha$-cloro aldeídos e cetonas foi avaliada. Em todos os casos a seletividade da reação foi explicada por esse modelo dipolar. Por exemplo, a adição do brometo de $n$-butilmagnésio ao $\alpha$-cloro butanal 7, à baixa temperatura, levou à formação do produto de adição $\mathbf{8}$ em $68 \%$ de rendimento, após tratamento com $\mathrm{AcOH}$, com diastereosseletividade de 70:30 em favor de $\mathbf{8 a}$, que apresentou a estereoquímica relativa anti (Esquema 7).

\section{Modelo de Karabatsos (1967)}

Em 1967, ${ }^{16}$ Karabatsos propôs um modelo baseado na hipótese de que a adição de um nucleófilo a aldeídos e cetonas, possuindo um centro estereogênico adjacente à carbonila, ocorreria através de um estado de transição similar ao reagente. Dessa forma, a conformação preferencial seria similar à conformação mais estável da molécula no estado fundamental, na qual a carbonila encontra-se eclipsada com o substituinte $R_{M}$ (Figura 4). O produto majoritário seria oriundo do ataque do nucleófilo em um ângulo de $90^{\circ}$, pela face contendo o menor substituinte $\left(\mathrm{R}_{\mathrm{P}}\right)$.

Nesses primeiros modelos propostos para a compreensão do curso estereoquímico observado em reações de adição à carbonila,

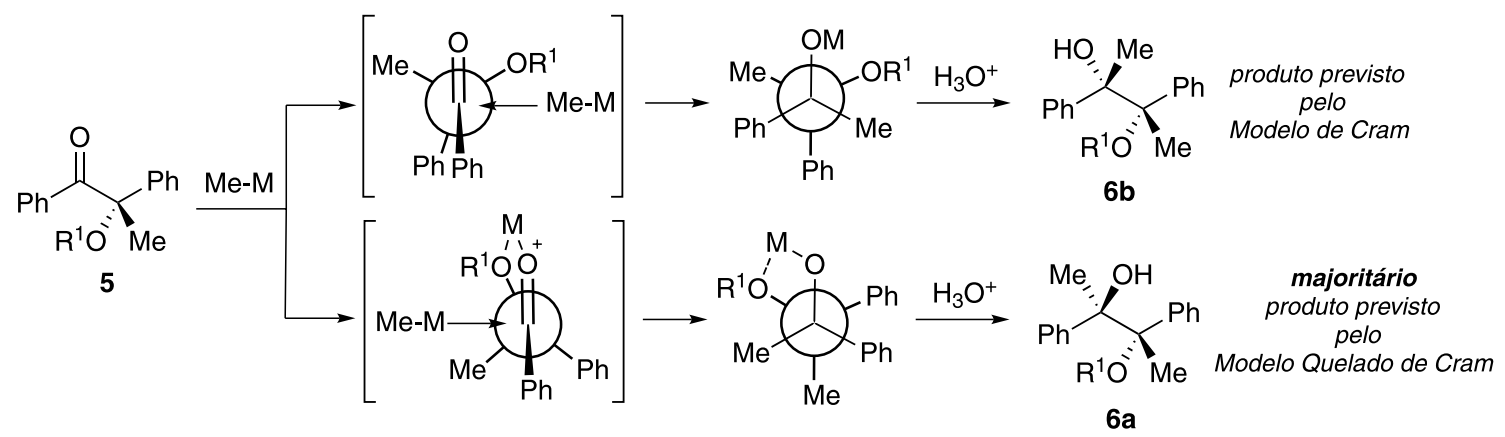




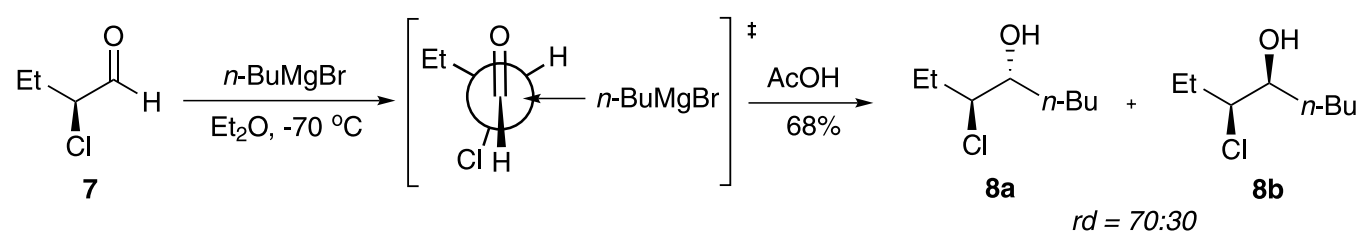

Esquema 7 - Estudos de Cornforth

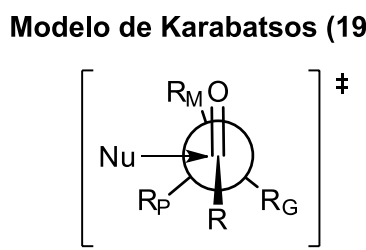

Figura 4 - Modelo de Karabatsos

Cram, Cornforth e Karabatsos propõem estados de transição de menor energia nos quais um dos substituintes do centro estereogênico $\alpha$-carbonila encontra-se eclipsado com a carbonila ou com o grupo ligado a ela. Atualmente, sabe-se que essa conformação possui maior energia em comparação com as conformações alternadas.

\section{Modelo de Felkin (1968)}

Em 1968, Felkin descreveu um modelo inovador, no qual efeitos torcionais foram levados em consideração e, pela primeira vez, uma proposta de estado de transição com ligações completamente alternadas foi apresentada. ${ }^{17} \mathrm{O}$ modelo de Felkin propõe um estado de transição no qual o nucleófilo aproxima-se em uma trajetória antiperiplanar em relação ao substituinte mais volumoso $\left(\mathrm{R}_{\mathrm{G}}\right)$ e entre os substituintes $\mathrm{R}_{\mathrm{P}}$ e $\mathrm{R}_{\mathrm{M}}$ (Figura 5).

\section{Modelo de Felkin (1968)}

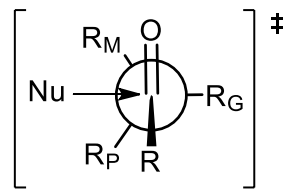

Figura 5 - Modelo de Felkin.

Considerando-se as possíveis conformações alternadas, a diastereosseletividade da reação seria resultante da diferença energética entre os dois estados de transição diastereoisoméricos de menor energia A e B (Figura 6). O produto majoritário seria resultado de uma reação através do estado de transição $\mathbf{A}$. Este seria favorecido em relação a $B$, porque a repulsão do $\mathrm{R}_{M}$ com a $\mathrm{C}=\mathrm{O}$ seria menos energética que a repulsão estérica entre $\mathrm{R}$ e $\mathrm{R}_{\mathrm{M}}$ no estado de transição $\mathbf{B}$.

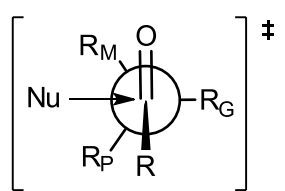

A

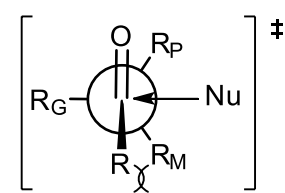

B
Figura 6 - Principais conformações reativas segundo o Modelo de Felkin
Apesar do sucesso na explicação de uma variedade de resultados experimentais, especialmente em reações com cetonas, algumas inconsistências ainda foram observadas no Modelo de Felkin:

- Efeito polar: grupos polares, não-quelantes (X), foram arbitrariamente posicionados perpendiculares ao plano da carbonila, na posição originalmente ocupada pelo grupo mais volumoso $\mathrm{R}_{\mathrm{G}}$ (Figura 7, estado de transição A).

- Inconsistência para aldeídos: quando o grupo R, ligado à carbonila é um hidrôgenio, não há interação estérica significativa entre $\mathrm{H}$ e $\mathrm{R}_{\mathrm{M}}$ e o estado de transição $\mathbf{C}$ deveria ser favorecido sobre $\mathbf{B}$, onde haveria maior interação estérica entre o oxigênio carbonílico e $\mathrm{R}_{\mathrm{M}}$. No entanto, essa hipótese não é observada experimentalmente, e o diastereoisômero resultante da adição via estado de transição A é formado preferencialmente (Figura 7, estados de transição $\mathbf{B}$ e $\mathbf{C}$ ).

\section{Modelo de Felkin-Anh (1977)}

Em 1977, Anh e Eisenstein fizeram um aprimoramento do modelo de Felkin pela incorporação da trajetória de Bürgi-Dunitz ${ }^{18} \mathrm{e}$ do efeito antiperiplanar. ${ }^{19}$

- Trajetória de Bürgi-Dunitz - Em 1973, Bürgi e Dunitz realizaram um elegante estudo cristalográfico em moléculas contendo em sua estrutura grupos amino e carbonila, cujas restrições estruturais caracterizavam uma adição "congelada" do nucleófilo à carbonila, permitindo assim o mapeamento do curso reacional. As evidências claramente indicaram que a trajetória de ataque do nucleófilo ocorre em um ângulo aproximado de $107^{\circ}$ em relação ao plano da carbonila, ao contrário do ataque perpendicular, apregoado à época (Figura 8a).

- Efeito Antiperiplanar - Em 1977, Anh e Eisenstein realizaram cálculos ab initio nos quais ficou evidente que o estado de transição de uma reação de adição à carbonila é estabilizado quando a ligação em formação entre o nucleófilo e o carbono carbonílico encontra-se com uma relação antiperiplanar com uma ligação sigma adjacente de menor energia (Figura 8b). Consequentemente, ocorre uma sobreposição orbitalar, com estabilização do sistema (Figura 8c). Quanto menor a energia do orbital antiligante $\sigma^{*}{ }_{\mathrm{C}-\mathrm{X}}$, maior a interação com o orbital preenchido da nova ligação $\sigma_{\mathrm{C}-\mathrm{Nu}} \mathrm{e}$ menor a energia do estado de transição. Seguindo esse raciocínio, quanto mais eletronegativo o átomo ligado ao carbono, menor a energia do orbital $\sigma_{\mathrm{C}-\mathrm{X}}$, conforme observado na Figura 9.

Essas evidências, ao serem incorporadas ao modelo introduzido por Felkin, levaram ao modelo de Felkin-Anh (Figura 10), que rapidamente tornou-se o modelo estereoquímico mais aceito para explicar e prever comportamentos de reações em sistemas carbonílicos contendo centros estereogênicos na posição $\alpha$-carbonílica.

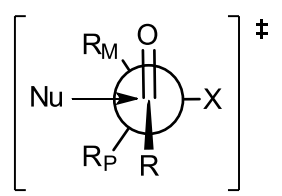

A

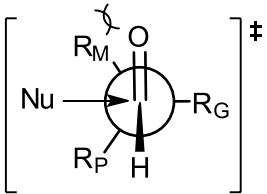

B

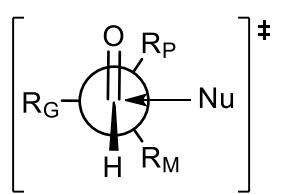

C

Figura 7 - Inconsistências observadas no Modelo de Felkin 
Trajetória de Bürgi-Dunitz

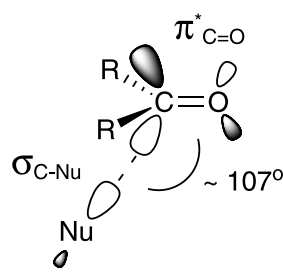

(a)

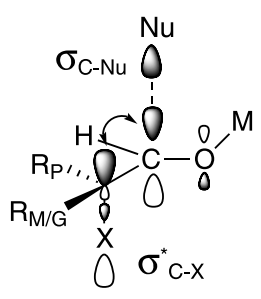

(b)
Efeito Antiperiplanar

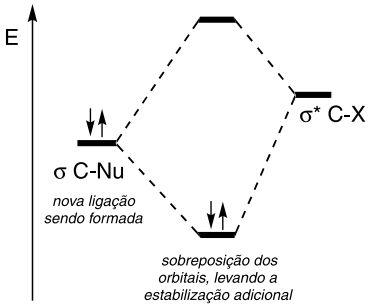

(c)

Figura 8 - Trajetória de Bürgi-Dunitz e Efeito Antiperiplanar

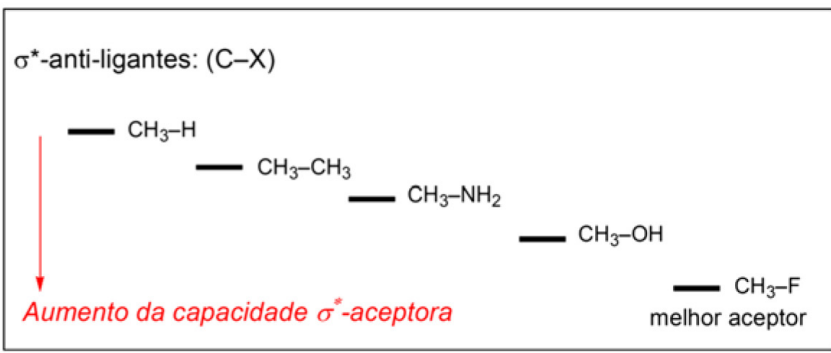

Figura 9 - Capacidade aceptora de ligações $C$ - $X$

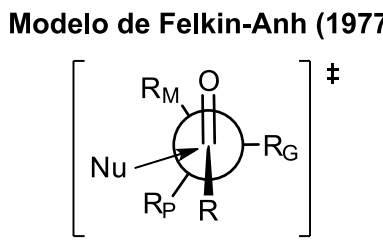

Figura 10 - Modelo de Felkin-Anh

O modelo de Felkin-Anh propõe que durante o ataque do nucleófilo a conformação energeticamente favorecida é aquela na qual o grupo mais volumoso fica perpendicular à carbonila e o ataque do nucleófilo ocorre pela face contrária a $R_{G}$. A repulsão estérica entre o nucleófilo e o substrato é minimizada mediante ataque do nucleófilo nas proximidades do grupo $\mathrm{R}_{\mathrm{P}}$, de acordo com a trajetória Bürgi-Dunitz. A incorporação dessa trajetória de ataque ao modelo permitiu compreender porque mesmo para aldeídos $(\mathrm{R}=\mathrm{H})$ o estado de transição preferencial é aquele no qual $R_{P}$ fica próximo a $R$. $O$ principal efeito que leva a essa conformação preferencial não é a repulsão entre $\mathrm{R}_{\mathrm{P} / \mathrm{M}} \mathrm{e} \mathrm{R}$, mas sim a repulsão entre o substituinte ligado ao carbono do centro estereogênico que interpõe-se à trajetória de ataque do nucleófilo.

A reação de adição de diferentes reagentes de Grignard ao aldeído 3 foi estudada (Esquema 8). ${ }^{20}$ Em todos os casos foi observada uma seletividade consistente com a prevista pelo modelo de Felkin-Anh, como resultado do ataque do nucleófilo na conformação A. Observase, no entanto, que a magnitude da seletividade varia de acordo com o volume estérico do nucleófilo utilizado. Quanto maior o tamanho da cadeia carbônica, maior a repulsão no estado de transição B, resultando em uma maior diferenciação energética entre os dois estados de transição diastereoisoméricos $\mathbf{A}$ e $\mathbf{B}$.

De modo similar, a redução da cetona $\mathbf{9}$ com tri-sec-butilboroidreto de lítio ocorre mediante o estado de transição previsto pelo modelo de Felkin-Anh, resultando no produto correspondente $\mathbf{1 0}$ com uma diastereosseletividade de 96:04 em favor do produto anti (Esquema 9). ${ }^{21}$

A diastereosseletividade da adição nucleofílica também é sensível a efeitos estereoeletrônicos. Isso fica bem evidente quando se observa a diferença de seletividade obtida para os aldeídos $\mathbf{9}$ e 11, que possuem como única diferença um substituinte no carbono $\alpha$ (Esquema 10). ${ }^{22} \mathrm{O}$ aldeído 11 possui uma ciclo-hexila como substituinte $\mathrm{R}_{\mathrm{G}}$, que é um substituinte mais volumoso que a fenila presente no aldeído 9. Entretanto, a seletividade obtida para o aldeído 9, com

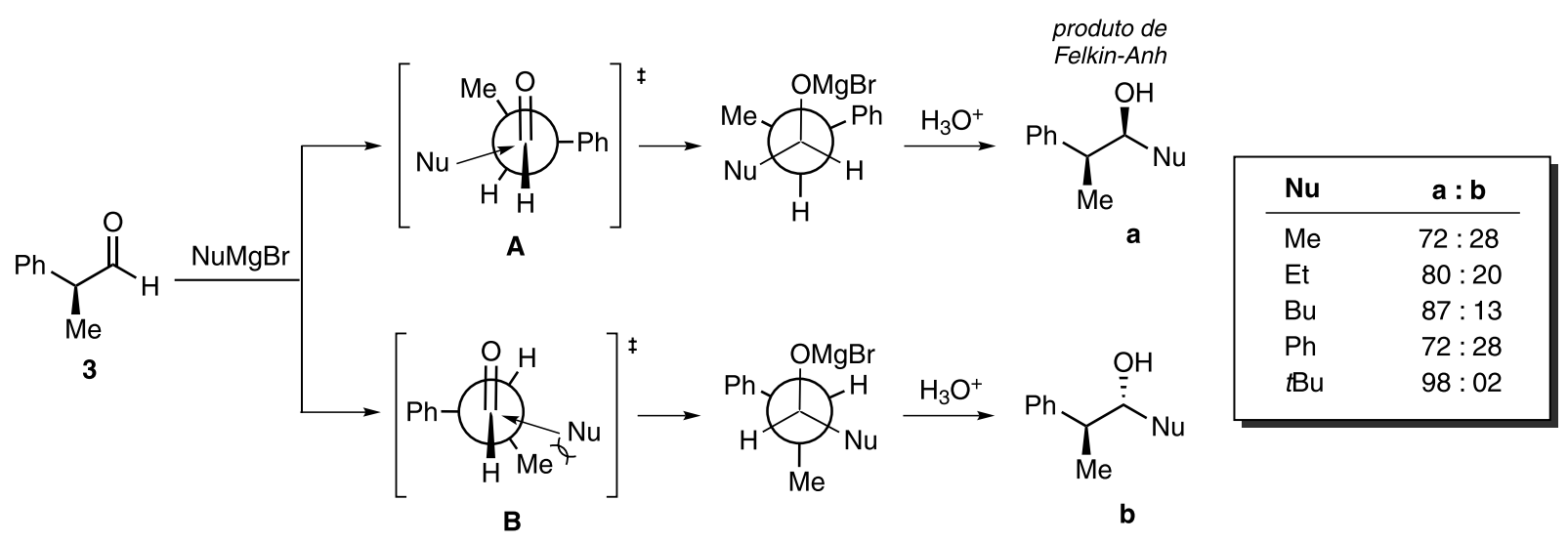

Esquema 8 - Adição de reagentes de Grignard ao aldeído 3

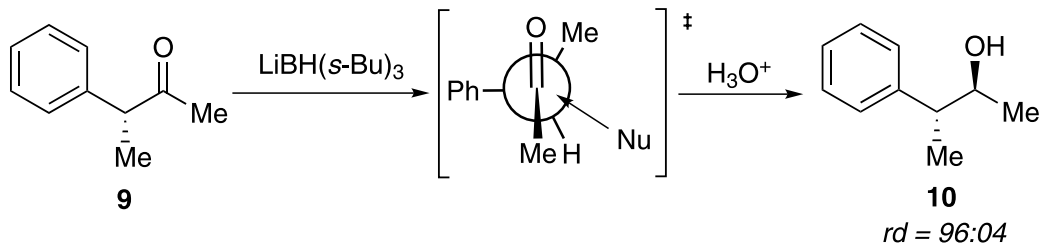



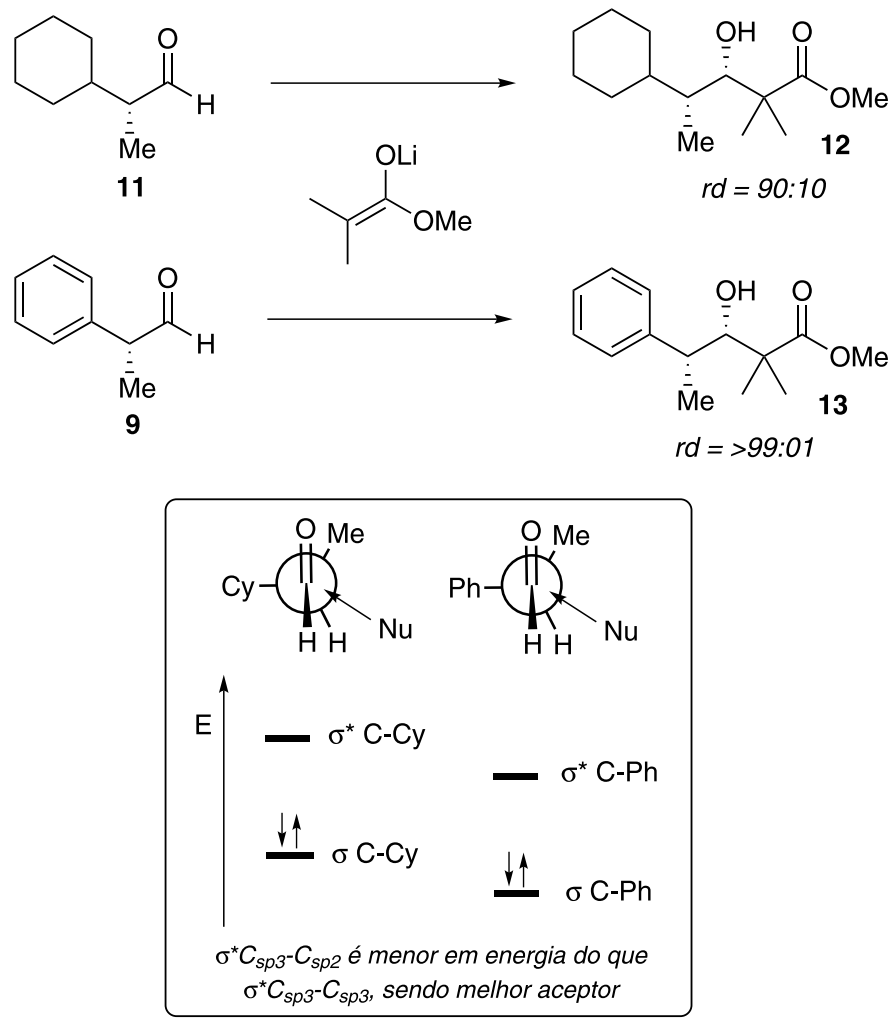

Esquema 10 - Seletividade sendo influenciada por efeito antiperiplanar

$\mathrm{R}_{\mathrm{G}}=\mathrm{Ph}$, é muito maior que aquela obtida para o aldeído $\mathbf{1 1}$, com $\mathrm{R}_{\mathrm{G}}=\mathrm{Cy}$. Esses resultados, portanto, não são explicados por volume estérico, mas sim por fatores estereoeletrônicos. Quando $\mathrm{R}_{\mathrm{G}}=\mathrm{Ph}$, o orbital $\sigma^{*} \mathrm{C}_{\mathrm{sp} 3}-\mathrm{C}_{\mathrm{sp} 2}$ é de menor energia e estando antiperiplanar ao ataque do nucleófilo, leva a uma maior estabilização desse estado de transição. Quanto melhor o aceptor do orbital $\sigma^{*}$ (menor energia) orientado antiperiplanar à formação da nova ligação $\sigma$, maior será a seletividade, porque o estado de transição é de menor energia.

Um outro exemplo interessante que evidencia também a importância do efeito antiperiplanar é a utilização do aldeído $\mathbf{1 4}$, com um substituinte trifluorometila no carbono $\alpha$, como substrato para a reação de adição de reagentes organometálicos (Esquema 11). ${ }^{23}$ Nesse caso, a diferença de tamanho entre os substituintes $\mathrm{CH}_{3}$ e $\mathrm{CF}_{3}$ é pequena e, ainda assim, a adição de diferentes nucleófilos procede de maneira estereosseletiva, levando aos produtos anti $\mathbf{1 5}$ e $\mathbf{1 6}$ prefencialmente, conforme previsto pelo modelo de Felkin-Anh. Os autores explicam as seletividades observadas pela presença de átomos de flúor, altamente eletronegativos, que resulta em uma diminuição da energia do orbital $\sigma^{*}$ da ligação $\mathrm{C}-\mathrm{CF}_{3}$, fazendo com que este grupo adote a posição antiperiplanar em relação ao ataque do nucleófilo.
O controle do substrato na formação de um novo centro estereogênico tem importância na síntese de uma variedade de produtos naturais e moléculas biologicamente relevantes. Recentemente, Kang e colaboradores descreveram a síntese total da inostamicina A, um produto natural isolado do caldo de fermentação de Streptomyces sp. MH816-AF15, e que apresenta atividade antimicrobiana e citotóxica. ${ }^{24}$ Devido ao seu mecanismo de ação, apresenta também a capacidade de regeneração da citotoxicidade do paclitaxel e supressão citostática de recorrência de tumores. Durante a rota sintética, a formação do álcool terciário $\mathbf{1 9}$ foi obtida mediante adição do reagente organolítio 17 à cetona 18 , na presença de $\mathrm{LaCl}_{3}$, que levou exclusivamente à formação do produto de Felkin 19 como único diastereoisômero (Esquema 12). Apesar da presença de um heteroátomo no carbono $\alpha$, este encontra-se impedido de quelação com o metal, pela presença do grupo mesila, que retira fortemente densidade eletrônica do oxigênio. Dessa forma, o grupo OMs fica antiperiplanar ao ataque do nucleófilo, já que possui orbital $\sigma^{*}{ }_{\mathrm{C}-\mathrm{O}}$ de menor energia.

Outro exemplo recente foi reportado por Zhu e colaboradores durante a síntese total e revisão estrutural do acetato da (+)-uprolida

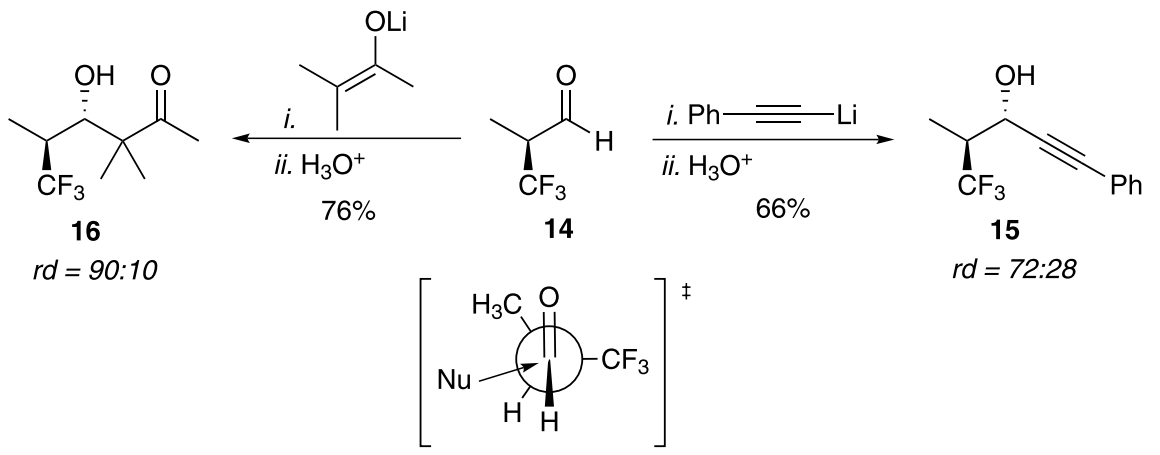




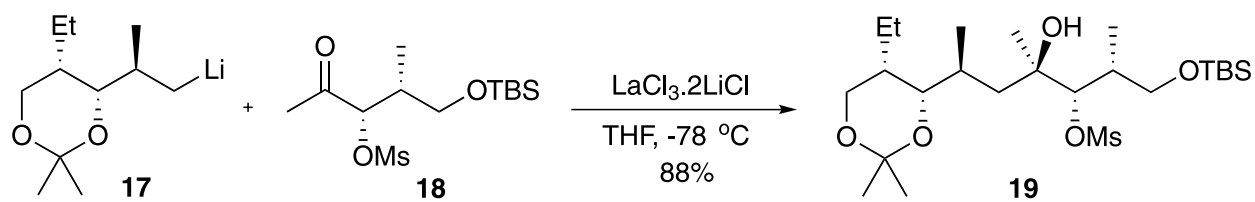

17

18

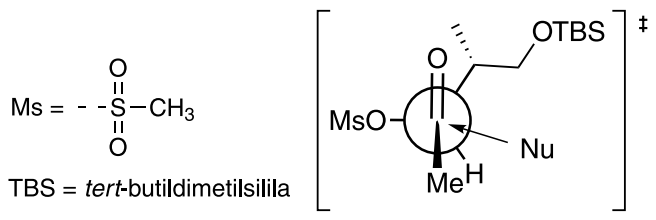

Esquema 12 - Etapa-chave na síntese da inostamicina A

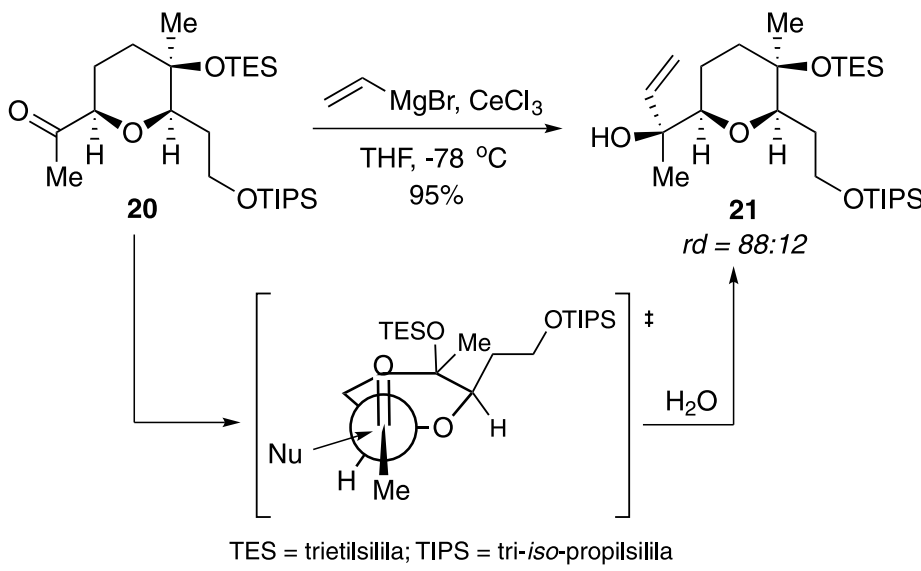

Esquema 13 - Controle Felkin-Anh na rota de síntese do acetato da (+)-uprolida $G$

G, um produto natural marinho membro da família das cembranolidas, com atividades citotóxicas. ${ }^{25} \mathrm{~A}$ adição de brometo de vinilmagnésio, na presença de $\mathrm{CeCl}_{3}$, à cetona $\mathbf{2 0}$ ocorreu em excelente rendimento e resultou no produto $\mathbf{2 1}$ em uma razão diastereoisomérica de 88:12 (Esquema 13). Sob as condições reacionais desenvolvidas pelos autores, a quelação com o oxigênio endocíclico é inibida pela presença do $\mathrm{Ce}(\mathrm{III})^{26}$ e a formação do diastereoisômero majoritário é explicada pelo modelo de Felkin-Anh.

\section{Modelo quelado de Cram atualizado}

Para compostos carbonílicos contendo substituintes em $\alpha$ capazes de quelação, muitas vezes as seletividades são explicadas pelo modelo quelado de Cram, o qual também foi atualizado pela incorporação da trajetória de Bürgi-Dunitz e pelo uso de uma conformação alternada no estado de transição (Figura 11). Os principais heteroátomos que se destacam em reações nas quais o controle estereoquímico é governado por quelação, com formação de um estado de transição de 5 membros, são oxigênio, nitrogênio e enxofre. Sistemas contendo esses heteroátomos
Modelo Quelado de Cram (1959)

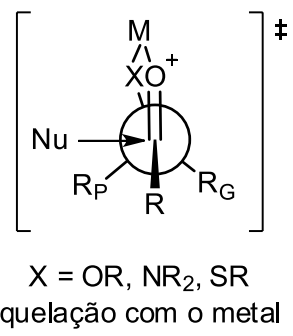

Modelo Quelado de Cram atualizado

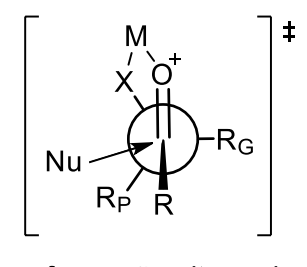

conformação alternada ângulo de ataque do $\mathrm{Nu}=107^{\circ}$
Figura 11 - Atualização do Modelo Quelado de Cram podem apresentar controle via quelação, dependendo dos substituintes ligados ao heteroátomo e das condições reacionais. A presença de grupos fortemente retiradores de elétrons ou muito volumosos ligados ao heteroátomo, geralmente previnem a quelação (ex.: Esquema 13). A eficiência da quelação está diretamente relacionada ao metal e os mais utilizados são $\mathrm{Li}^{+}$(algumas vezes), $\mathrm{Mg}^{2+}, \mathrm{Zn}^{2+}, \mathrm{Cu}^{2+} \mathrm{e} \mathrm{Ti}{ }^{4+}$. Metais que tipicamente não participam de quelação são $\mathrm{Na}^{+}$e $\mathrm{K}^{+}$.

As seletividades obtidas por controle quelado são normalmente bem pronunciadas quando metais eficientes em promover a quelação com a carbonila e o substituinte em $\alpha$ são utilizados. Quando se compara a adição de reagentes organomagnésio e organolítio à cetona $\mathbf{2 2}$, observa-se que o reagente organomagnésio possui melhor eficiência na quelação, levando ao produto 23a com alta diastereosseletividade. ${ }^{27}$ Por outro lado, o uso do reagente organolítio leva a um mistura praticamente equimolar de diastereoisômeros (Esquema 14).

A utilização de um substrato com um substituinte sulfurado $\mathbf{2 4}$ permite a obtenção do produto $\mathbf{2 5 b}$ por redução com boroidreto de zinco, através de um estado de transição quelado. Por outro lado, a utilização de $\mathrm{LiBu}_{3} \mathrm{BH}$ levou à uma reação com controle via modelo de Felkin-Anh e o diastereoisômero oposto 25a foi obtido exclusivamente (Esquema 15). ${ }^{28}$

Um exemplo interessante no qual o controle por quelação foi crucial para a formação da estereoquímica desejada durante a síntese total do ácido (+)-zaragozico C foi descrito por Carreira e Du Bois (Esquema 16). Uma das etapas da síntese envolveu a adição de um reagente organometálico 27 à cetona $\alpha$-oxigenada 26 , levando ao álcool terciário $\mathbf{2 8}$ em $84 \%$ de rendimento e diastereosseletividade $>95: 05$, seguindo o modelo quelado de Cram. ${ }^{29}$

Um elegante estudo descrito por Overman e McCready mostrou a influência da natureza do grupo protetor de oxigênio e das condições reacionais, na seletividade da redução de cetonas contendo um centro estereogênico na posição $\alpha$-carbonílica (Esquema 17). ${ }^{30}$ Quando o 


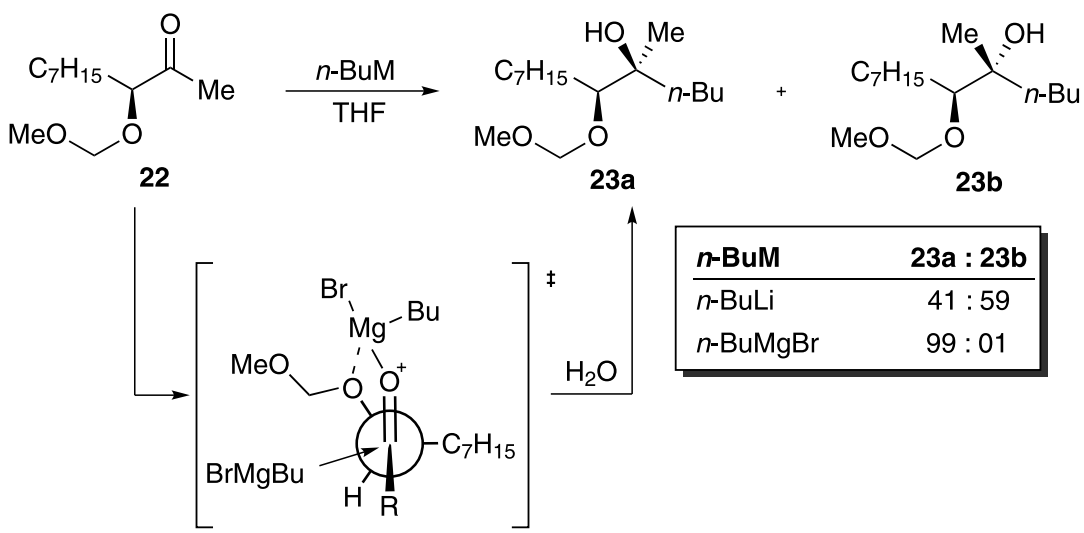

Esquema 14 - Seletividade dependente do metal

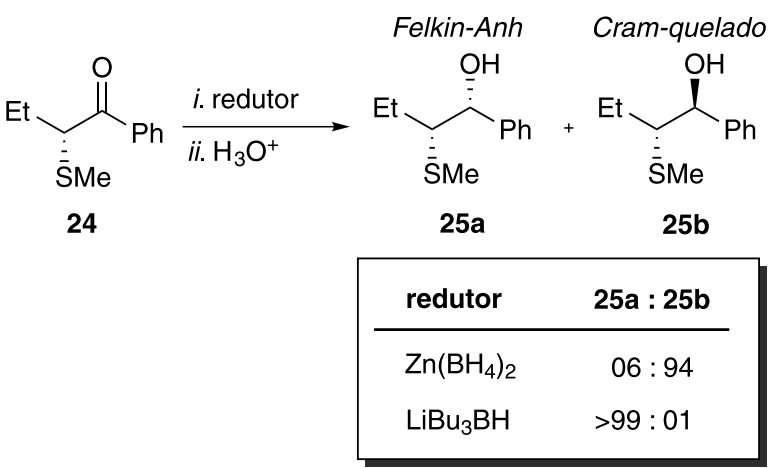

Esquema 15 - Seletividade na redução de $\alpha$-tiometilcetona

substrato contendo o grupo $\mathrm{CH}_{2} \mathrm{OBn}$ como protetor foi submetido à redução com $\mathrm{LiAlH}_{4}$, em THF como solvente, o produto majoritário da reação foi 31, resultante de um controle via modelo quelado de Cram, em uma diastereosseletividade moderada (30:70). A substituição do solvente de THF por éter etílico resultou em um melhora substancial da seletividade da reação e o produto $\mathbf{3 1}$ foi obtido quase que exclusivamente. A razão do aumento da seletividade deve-se à menor basicidade do $\mathrm{Et}_{2} \mathrm{O}$ em comparação com o THF, portanto, favorecendo com que ocorra a quelação do átomo metálico com os dois oxigênios do substrato, ao invés de coordenação com os oxigênios do solvente. Por outro lado, quando o grupo protetor foi alterado para um grupo sililado e volumoso (tert-butildifenilsilila, TBDPS), a seletividade da reação de redução foi completamente invertida e o produto majoritário observado foi $\mathbf{3 0}$, em uma excelente seletividade de 95:05. A utilização do protetor de silício previne a quelação do oxigênio $^{31}$ e a seletividade da redução passa a ser governada pelo modelo de Felkin-Anh, com o grupo OTBPDS ocupando a posição antiperiplanar em relação ao ataque do agente redutor.

Um exemplo ilustrativo da influência de protetores de silício sobre a capacidade de evitar a quelação do oxigênio com metais pode ser observado no Esquema 18. Durante a síntese total do agente anti-fúngico sorafeno A, Trost e colaboradores descreveram a adição de um acetileto de lítio, gerado pela reação de 32 com $n$-BuLi, a um aldeído quiral 33. ${ }^{32}$ A presença de um grupo protetor sililado no átomo de oxigênio do centro $\alpha$-carbonila previne a quelação e a seletividade da reação é resultado do posicionamento do grupo OTBS antiperiplanar ao ataque do nucleófilo. Dessa forma, o produto majoritário $\mathbf{3 4}$, apresentando estereoquímica relativa anti

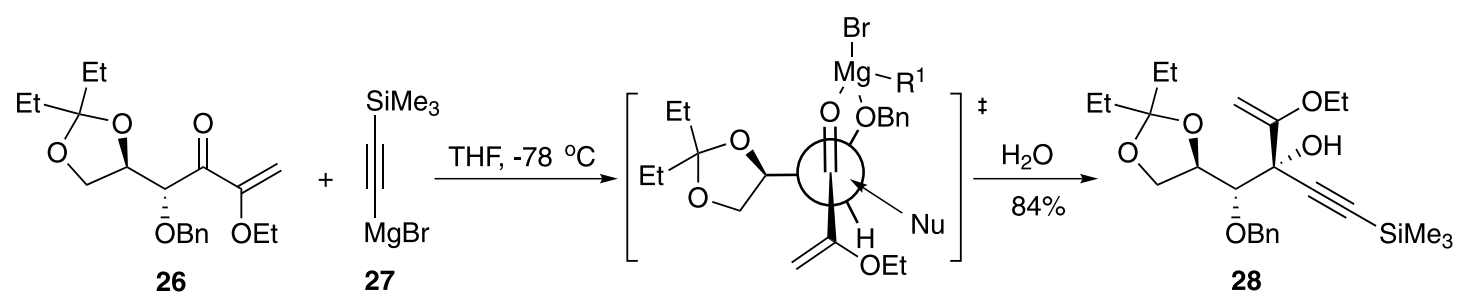

Esquema 16 - Controle por quelação em etapa-chave da síntese do ácido (+)-zaragozico C<smiles>CC=C(C)C(=O)C(C)OC1CCCCC1</smiles>

GP = grupo protetor

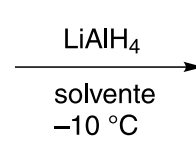




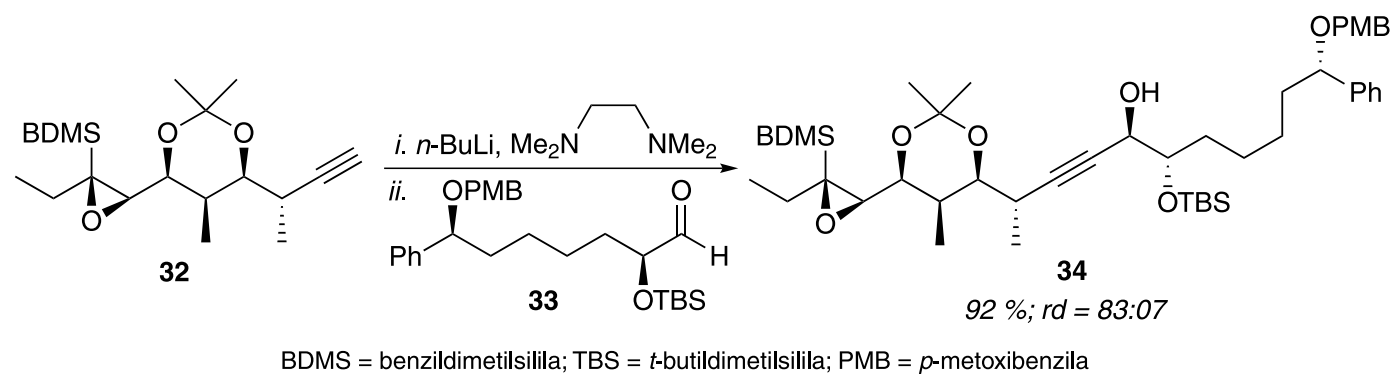

Esquema 18 - Controle Felkin-Anh na rota de síntese do sorafeno A

entre os dois carbonos oxigenados, é resultado de um controle via modelo de Felkin-Anh.

\section{Modelo de Cornforth atualizado: Modelo de Cornforth-Evans (2003)}

O modelo de Cornforth foi revisitado em 2003 por Evans, durante estudos do curso estereoquímico de reações aldólicas diastereosseletivas utilizando aldeídos contendo substituintes polares e não-quelantes na posição $\alpha$-carbonílica (Figura 12) ${ }^{33,34}$ As modificações introduzidas por Evans envolvem basicamente uma atualização do modelo originalmente proposto por Cornforth, através da incorporação de efeitos torcionais (conformação alternada) e da trajetória de Bürgi-Dunitz.

O modelo Cornforth-Evans pressupõe que a conformação preferencial adotada pela molécula durante o ataque do nucleófilo é aquela em que ocorre a minimização dos dipolos no estado de transição. À medida em que a nova ligação vai sendo formada, há um alinhamento

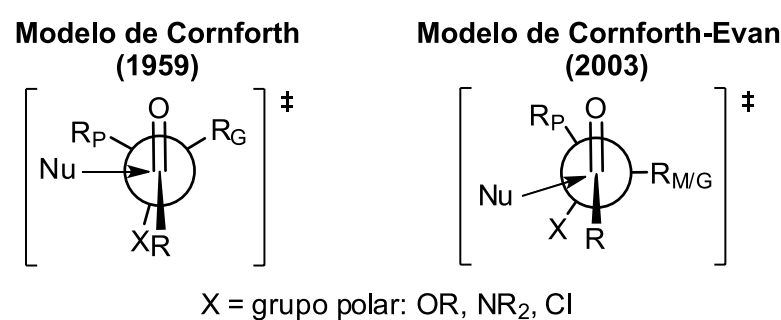

Figura 12 - Comparação dos Modelos de Cornforth e Cornforth-Evans antiperiplanar entre o substituinte $\mathrm{X}$ e a ligação C-O, o que estabilizaria o sistema (Esquema 19).

Cabe salientar que tanto o modelo de Felkin-Anh quanto o de Cornforth-Evans levam à previsão do mesmo produto em uma reação de adição de um nucleófilo a um composto carbonílico contendo um substituinte polar e não-quelante na posição $\alpha$, embora envolvam proposições de estados de transição ocorrendo através de diferentes confôrmeros (Esquema 20).

Em 1987, Heathcock e Lodge desenvolveram estudos da reação aldólica entre o enolato de lítio da pinacolona 36 com uma série de aldeídos quirais $\alpha$-oxigenados 35 e as seletividades analisadas com base no modelos de Felkin-Anh (Esquema 21). ${ }^{35}$ De acordo com o modelo de Felkin-Anh, o ataque do nucleófilo ocorre preferencialmente de maneira antiperiplanar ao substituinte com menor energia do orbital $\sigma^{*}$. Dessa forma, para a série de aldeídos examinada, essa posição seria ocupada pelo grupo OMe e o produto majoritário da reação aldólica seria 37a-anti, como resultado de uma adição preferencial mediante o estado de transição $\mathbf{A}$. Um decréscimo na magnitude da seletividade seria esperado com um aumento no tamanho do grupo R, devido a um aumento na repulsão estérica entre o oxigênio carbonílico e R, desestabilizando o estado de transição A, o que resultaria em um favorecimento do estado de transição $\mathbf{C}$, no qual a face oposta da carbonila seria atacada, aumentando assim a proporção do diastereoisômero 37b-syn. Em todos os casos estudados, o produto 37a-anti foi formado majoritariamente, no entanto, um comportamento exatamente oposto em relação à magnitude da seletividade foi observado experimentalmente, havendo um aumento da seletividade com o aumento do

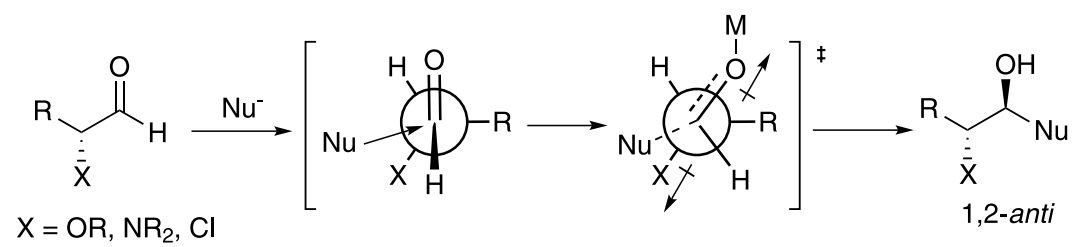

Esquema 19 - Minimização de dipolos no estado de transição segundo modelo de Cornforth-Evans

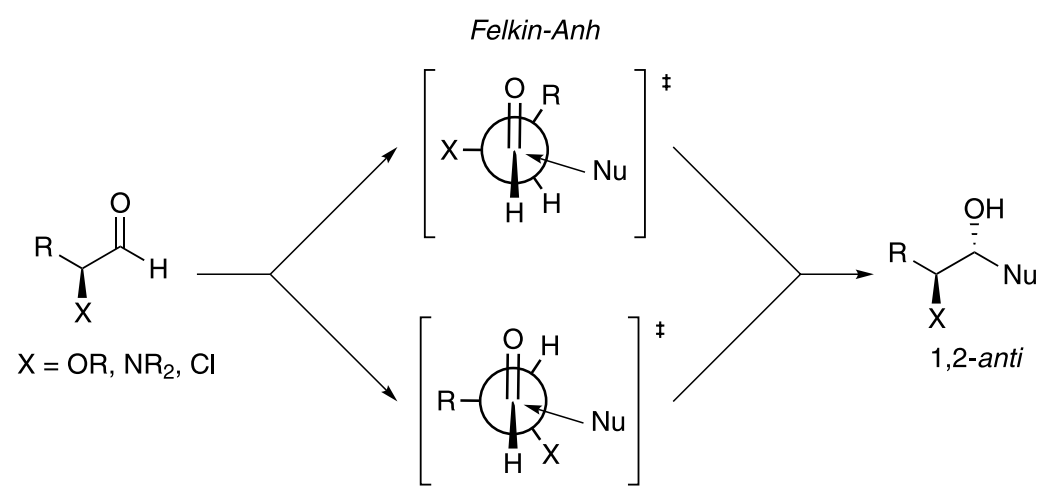

Cornforth-Evans 

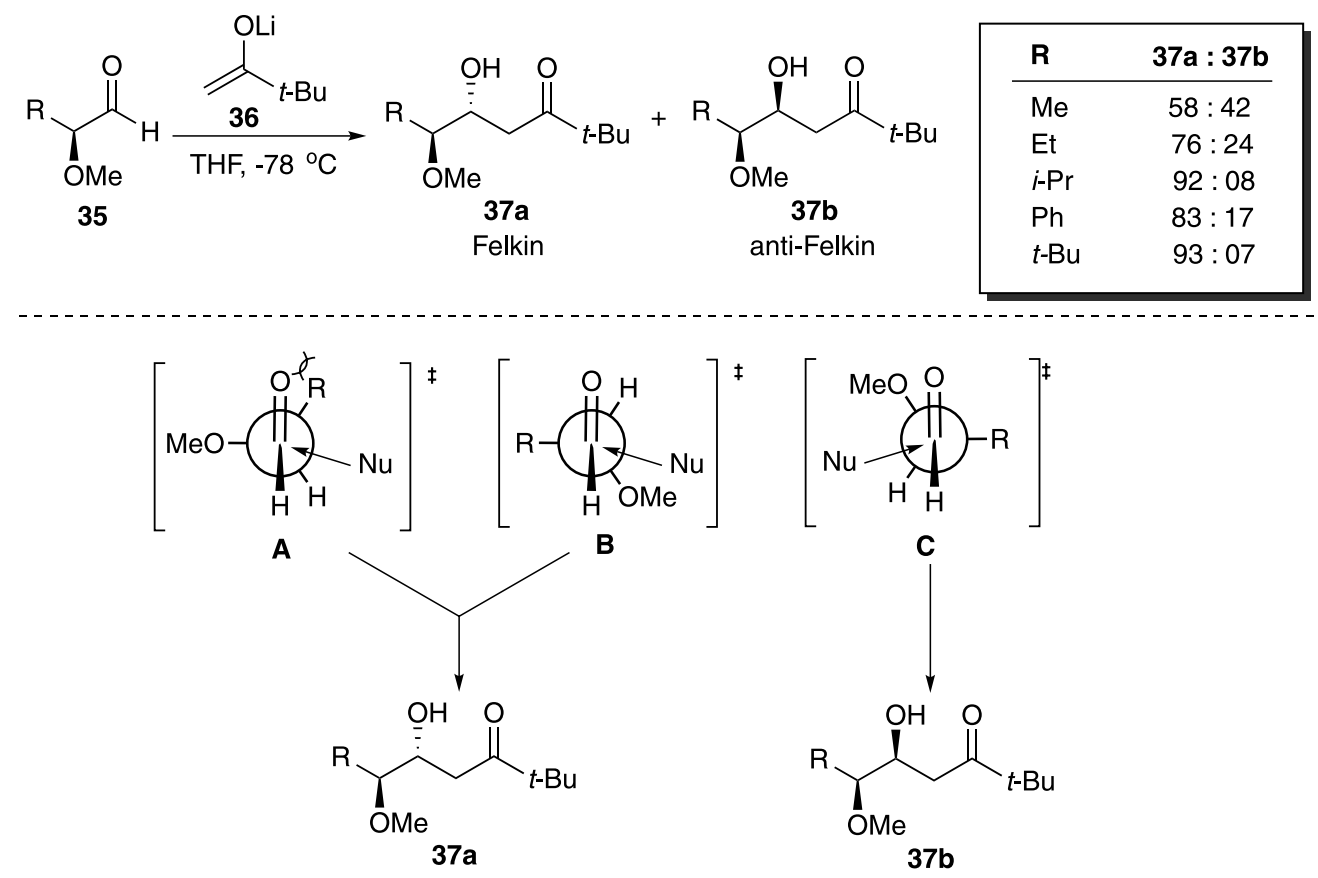

Esquema 21 - Seletividade da reação aldólica: Modelo de Felkin-Anh x Cornforth-Evans

grupo R. Essas observações levaram os autores a concluir, na época, que "Nossos resultados podem ser acomodados dentro dos princípios fundamentais do modelo de Felkin para indução 1,2. Eles estão em concordância geral com a racionalização de Anh-Eisenstein para o modelo de Felkin. No entanto, acreditamos que a racionalização é incompleta e que as energias dos orbitais $\sigma^{*}$ deve ser contrabalanceada com efeitos estéricos." Analisando-se os dados obtidos por Heathcock e Lodge, utilizando o modelo de Cornforth-Evans, uma melhor compreensão dos resultados pode ser alcançada. Ao considerar-se que a minimização dos dipolos no estado de transição possui um papel relevante na diminuição da energia do mesmo, o estado de transição B (Esquema 21) seria favorecido. Dessa forma, o grupo R ocuparia a posição antiperiplanar em relação ao nucleófilo e quanto maior o tamanho de R, maior seria a contribuição do estado de transição $\mathbf{B}$ e, consequentemente, maior a seletividade da reação.

Mais recentemente, $\alpha$-cloro aldeídos têm sido frequentemente utilizados como substratos para a síntese de produtos naturais, principalmente de origem marinha. ${ }^{36}$ Dentro desse contexto, o modelo de Cornforth-Evans tem sido usado para racionalizar o curso estereoquímico de reações envolvendo esses substratos e reagentes organometálicos. Por exemplo, a adição do acetileto de lítio ao $\alpha$-cloro aldeído 38 foi descrita por Vanderwal em estudos na síntese de clorossulfolipídeos, uma classe de moléculas polialogenadas isoladas de organismos marinhos e que apresentam arranjos estruturais e estereoquímicos complexos (Esquema 22). ${ }^{37}$ Essa classe de moléculas possui um significativo potencial biológico ainda não completamente

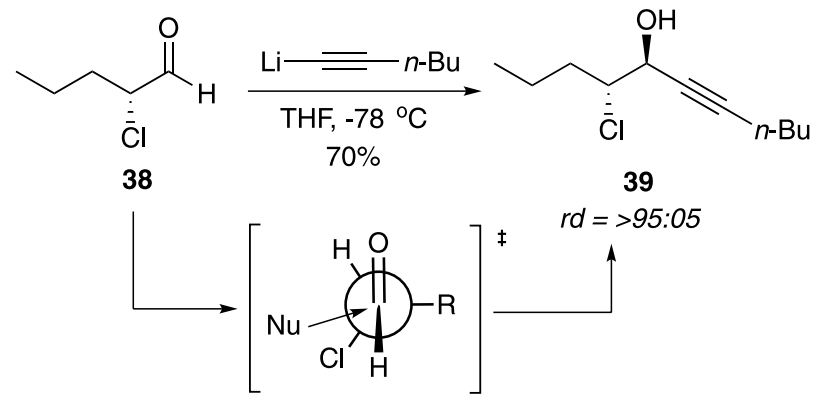

Esquema 22 - Alquinilação $\alpha$-cloro aldeído 38 acessível, principalmente devido a limitações de métodos eficientes para sua síntese estereosseletiva.

\section{CONCLUSÃO}

A utilização de reações de adição diastereosseletiva de nucleófilos a aldeídos e cetonas é uma transformação fundamental em química orgânica, que permite um aumento na complexidade molecular através da formação de novas ligações, acompanhadas de controle sobre a formação de um novo centro estereogênico. Dentro desse contexto, os modelos estereoquímicos de adição à carbonila são um valiosa ferramenta para a compreensão de resultados obtidos experimentalmente e, principalmente, para a previsão de comportamento de sistemas ainda não estudados. Atualmente três modelos são amplamente utilizados para explicar as seletividades observadas em reações de adição à carbonila. O modelo de Felkin-Anh é utilizado para substratos que não possuem heteroátomos no centro estereogênico $\alpha$-carbonila. O modelo Quelado de Cram é utilizado para substratos contendo heteroátomos capazes de quelação com metais. Quando um substituinte polar e não-quelante está presente no centro estereogênico $\alpha$-carbonila, as seletividades são explicadas tanto pelo modelo de Felkin-Anh quanto pelo modelo de Cornforth-Evans. No entanto, este último tem se mostrado mais eficiente para explicar a magnitude das seletividades observadas. Esperamos que a discussão apresentada ao longo do presente trabalho sirva de base para que os estudantes sejam capazes de compreender não somente os resultados observados, mas também os conceitos que suportam os modelos apresentados.

\section{AGRADECIMENTOS}

Os autores agradecem à CAPES, ao CNPq e à FAPERGS pelo auxílio financeiro. O CNPq é agradecido pela bolsa de doutorado de B.S.M.

\section{REFÊRENCIAS}

1. Carreira, E. M.; Kvaerno, L. E.; Classics in Stereoselective Synthesis, Wiley-VCH: Weinheim, 2009; Nicolaou, K. C.; Sorensen, E. J.; Classics 
in Total Synthesis, Wiley-VCH: Weinheim, 1996; Nicolaou, K. C.; Snyder, S. A.; Classics in Total Synthesis II, Wiley-VCH: Weinheim, 2003; Nicolaou, K. C.; Chen, J. S.; Classics in Total Synthesis III; Wiley-VCH: Weinheim, 2011; Hudlicky, T.; Reed, J. W.; The Way of Synthesis, WileyVCH: Weinheim, 2007.

2. Mengel, A.; Reiser, O.; Chem. Rev. 1999, 99, 1191; Gung, B. W.; Tetrahedron 1996, 52, 5263; Reetz, M. T.; Angew. Chem., Int. Ed. Engl. 1984, 23, 556 .

3. Bruice, P. Y.; Química Orgânica, $4^{\mathrm{a}}$ ed., Pearson Prentice Hall: São Paulo, 2006; McMurry, J. Química Orgânica, $7^{\mathrm{a}}$ ed., Cengage Learning: São Paulo, 2011; Solomons, T. W. G.; Fryhle, C. B.; Química Orgânica, $10^{\mathrm{a}}$ ed., LTC: Rio de Janeiro, 2012; Vollhardt, K. P. C.; Schore, N. E.; Química Orgânica Estrutura e Função, 6ª ed., Bookman: Porto Alegre, 2013.

4. Clayden, J.; Greeves, N.; Warren, S.; Organic Chemistry; Oxford University Press: Oxford, 2012, $2^{\text {nd }}$ ed., pp. 858; Costa, P. R. R.; Pilli, R. A.; Pinheiro, S.; Vasconcellos, M. L. A. A.; Substâncias Carboniladas e Derivados, Artmed Editora: Porto Alegre, 2003, pp. 128; Constantino, M. G.; Química Orgânica, Vol 2, LTC: Rio de Janeiro, 2008, pp. 234.

5. Fischer, E.; Ber. Dtsch. Chem. Ges. 1890, 23, 2611.

6. Fischer, E.; Ber. Dtsch. Chem. Ges. 1894, 27, 3189.

7. Fischer, E.; Ber. Dtsch. Chem. Ges. 1891, 24, 1836; Fischer, E.; Ber. Dtsch. Chem. Ges. 1891, 24, 2683.

8. Para uma revisão veja: Lichtenthaler, F. W.; Angew. Chem. Int. Ed. Engl. 1992, 31, 1541.

9. Cram, D. J.; Elhafez, F. A. A.; J. Am. Chem. Soc. 1952, 74, 5828.

10. A razão diastereoisomérica $(r d)$ é definida como a proporção de um diastereoisômero em relação aos demais diastereoisômeros presentes em uma mistura.

11. Nas publicações originais, as proporções dos diastereoisômeros são reportadas de diferentes formas, principalmente $x: 1$ ou como somatória de 100\% (ex.: $r d=95: 05$ ). Para fins de formatação e para permitir uma comparação mais direta entre diferentes resultados, a última é adotada ao longo de todo o artigo, uma vez que acreditamos permitir ao estudante uma mais rápida correlação da seletividade observada com a diferença energética que controla a formação dos produtos.

12. Por razões históricas e para uma melhor comparação entre diferentes modelos, projeções de Newman são utilizadas para a visualização das conformações no estado de transição.

13. Os valores-A foram obtidos a partir de estudos envolvendo tendências relativas de posicionamento de diferentes grupos em posições equatoriais em ciclo-hexanos substituídos: Winstein, S.; Holness, N. J.; J. Am. Chem. Soc. 1955, 77, 5562.

14. Cram, D. J.; Kopecky, K. R.; J. Am. Chem. Soc. 1959, 81, 2748.

15. Cornforth, J. W.; Cornforth, R. H.; Mathew, K. K.; J. Chem. Soc. 1959, 112.
16. Karabatsos, G. J.; J. Am. Chem. Soc. 1967, 89, 1367.

17. Chérest, M.; Felkin, H.; Prudent, N.; Tetrahedron Lett. 1968, 9, 2199.

18. Bürgi, H. B.; Dunitz, J. D.; Shefter, E.; J. Am. Chem. Soc. 1973, 95, 5065; Bürgi, H. B.; Dunitz, J. D.; Lehn, J. M.; Wipff, G.; Tetrahedron 1974, 30, 1563.

19. Anh, N. T.; Eisenstein, O.; Nouv. J. Chim. 1977, 1, 61.

20. Alvarez-Ibarra, C.; Arjona, O.; Pérez-Ossorio, R.; Pérez-Rucalcaba, A.; Quiroga, M. L.; Santesmases, M. J.; J. Chem. Soc., Perkin Trans. 2 1983, 1645 .

21. Midland, M. M.; Kwon, Y. C.; J. Am. Chem. Soc. 1983, 105, 3725.

22. Flippin, L. A.; Onan, K. D.; Tetrahedron Lett. 1985, 26, 973.

23. Yamazaki, T.; Kobayashi, R.; Kitazume, T.; Kubota, T.; J. Org. Chem. 2006, 71, 2499.

24. Yu, G.; Jung, B.; Lee, H.; Kang, S. H.; Angew. Chem. Int. Ed. 2016, 55 , 2573.

25. Zhu, L.; Liu, Y.; Ma, R.; Tong, R.; Angew. Chem. Int. Ed. 2015, 54, 627.

26. Para uma discussão sobre o papel do Ce(III) como ácido de Lewis nãoquelante em reações diastereosseletivas, veja: Bartoli, G.; Bosco, M.; Dalpozzo, R.; Marcantoni, E.; Sambri, L.; Chem. Eur. J. 1997, 3, 1941; Marcantoni, E.; Cingolani, S.; Bartoli, G.; Bosco, M.; Sambri, L.; J. Org. Chem. 1998, 63, 3624.

27. Still, W. C.; McDonald, J. H.; Tetrahedron Lett. 1980, 21, 1031.

28. Shimagaki, M.; Maeda, T.; Matsuzaki, Y.; Hori, I.; Nakata, T.; Oishi, T.; Tetrahedron Lett. 1984, 25, 4775.

29. Carreira, E. M.; Du Bois, J.; J. Am. Chem. Soc. 1994, 116, 10825; Carreira, E. M.; Du Bois, J.; J. Am. Chem. Soc. 1995, 117, 8106.

30. Overman, L. E.; McCready, R. J.; Tetrahedron Lett. 1982, 23, 2355.

31. Uma discussão mais detalhada sobre influencia de grupos protetores de silício na basicidade do oxigênio pode ser vista em: Shambayati, S.; Blake, J. F.; Wierschke, S. G.; Jorgensen, W. L.; Schreiber, S. L.; J. Am. Chem. Soc. 1990, 112, 697.

32. Trost, B. M.; Sieber, J. D.; Qian, W.; Dhawan, R.; Ball, Z. T.; Angew. Chem. Int. Ed. 2009, 48, 5478.

33. Evans, D. A.; Siska, S. J.; Cee, V. J.; Angew. Chem. Int. Ed. 2003, 42, 1761

34. Cee, V. J.; Cramer, C. J.; Evans, D. A.; J. Am. Chem. Soc. 2006, 128, 2920.

35. Lodge, E. P.; Heathcock, C. H.; J. Am. Chem. Soc. 1987, 109, 3353; veja também Lodge, E. P.; Heathcock, C. H.; J. Am. Chem. Soc. 1987, 109, 2819 .

36. Britton, R.; Kang, B.; Nat. Prod. Rep. 2013, 30, 227.

37. Shibuya, G. M.; Kanady, J. S.; Vanderwal, C. D.; J. Am. Chem. Soc. 2008, 130, 12514. 